\title{
Manuel Morales: Obituary
}

\author{
Julian Borejdo
}

Published online: 5 January 2010

(C) Springer Science+Business Media B.V. 2010

Manuel Francisco Morales died on November 12, 2009. He was born in San Pedro, Sula, Honduras, on July 23, 1919. He received secondary and college education (A. B., U. California Berkeley) and graduate training at Harvard (Mathematics/Physics) and U. California Berkeley (Physiology/Biophysics). During WWII, he served as a line officer on the USS Washington and staff officer in the US Naval Reserve. After the war he was a faculty member at the University of Chicago, the Naval Medical Research Institute, the Dartmouth Medical School, and the University of California, San Francisco. His abiding interest was the molecular basis of muscle contraction. His first significant scientific breakthrough came in 1956 when together with R. Podolsky he determined the heat of hydrolysis of ATP. He also showed, together with T. L. Hill, that the free energy of ATP hydrolysis originated in the coulombic repulsion between the $\gamma$ and $\alpha$ and $\beta$ phosphates. Together with a long-time collaborator, J. Botts, he was able to describe the kinetic behavior of enzyme-catalyzed systems. He was the first to apply G. Weber's orientational fluorescence probe to study muscle, and together with collaborators such as R. A. Mendelson, J. Botts, C. Dos Remedios, S. Highsmith and T. P. Burghardt suggested that rotation of myosin cross-bridges requires the participation of myosin S1 and actin. He was the first to use FRET in muscle to construct the 3-dimensional map of myosin. Following retirement in 1989, he worked with H. Ohnishi as a Research Professor at the University of the Pacific. Dr. Morales was the eighth Career Investigator of the American Heart Association; he was also a President of the Biophysical Society, the Founding Editor of the Annual Review of Biophysics, and a Fogarty Scholar-in-Residence at the US National Institutes of Health. Dr. Morales was a member of the National Academy of Sciences (USA), received the Order of the Rising Sun (Japan), and held an honorary doctorate from the University of the Pacific.

J. Borejdo $(\bowtie)$

University of North Texas Health Science Center,

Fort Worth, TX, USA

e-mail: jborejdo@hsc.unt.edu 